九州大学学術情報リポジトリ

Kyushu University Institutional Repository

\title{
A Two-Dimensional Simulation of Flow Field in Lakes under Wind Acting on the Water Surface and the Impact of Aquatic Plants on the Flow Patterns
}

Lap, Bui Quoc

Graduate School of Bioresource and Bioenvironmental Sciences, Kyushu Unviersity

Mori, Ken

Faculty of Agriculture, Kyushu Unviersity

https://doi.org/10.5109/4703

出版情報: 九州大学大学院農学研究院紀要. 51 (1)，pp.13-18，2006-02-01. Faculty of Agriculture， Kyushu University

バージョン :

権利関係 : 


\title{
A Two-Dimensional Simulation of Flow Field in Lakes under Wind Acting on the Water Surface and the Impact of Aquatic Plants on the Flow Patterns
}

\author{
Bui Quoc LAP ${ }^{1}$ and Ken MORI*
}

\author{
Laboratory of Bioproduction and Environment Information Sciences, Division of Bioproduction and Environment \\ Information Sciences, Department of Bioproduction and Environment Science, Faculty of Agriculture, \\ Kyushu University, Fukuoka 812-8581, Japan \\ (Received October 24, 2005 and accepted November 16, 2005)
}

\begin{abstract}
Circulation in lakes, which is primarily caused by wind shear acting on the water surface, is one of the key issues in the field of water environment. Therefore, simulating wind-induced flows in lakes is great of significance. The objective of this research is to build a two-dimensional, unsteady, laterally averaged model for simulating flow field in lakes. The main foundation of the model is the incompressible Navier-Stokes equations for two dimensions laterally and vertically. In this research, these equations were discretized by the finite volume method (FVM), and were solved for flow field velocities by the SIMPLE (Semi-Implicit Method for Pressure-Linked Equations) algorithm (Patankar, 1980) with the variables defined on a space-staggered rectangular grid. To solve these equations effectively, a numerical method has been developed by using the Tri-Diagonal Matrix Algorithm (TDMA), and a software program has been coded in Fortran 90 (Nyhoff and Leestma, 1997; 1999) to implement the algorithm. To verify the model, Tabiishidani lake was chosen as a case study. Tabiishidani lake's cross-section size and meteorological data were observed and used as the boundary conditions for the model. After coding, the model was used to simulate the wind-induced flow patterns in the lake under the different areas covered by aquatic plants on the water surface.
\end{abstract}

\section{INTRODUCTION}

Lakes and reservoirs are major surface water sources for life. They provide a multitude of uses including drinking, municipal water supply, power generation, navigation, agricultural irrigation, etc., and are prime regions for human settlement and habitation, but they may be also subject to pollution caused by these and other activities, which may degrade their water quality. Therefore, lakes and reservoirs are still the subject of great environmental concern. One of the key issues which have drawn attention from researchers in the field of water environment so far is circulation in lakes and reservoirs because it is closely related to questions of environmental protection, water supply and ecology (Sündermann, 1979). Circulation in lakes is primarily caused by wind shear acting on the water surface, affected partly by density gradients, aquatic plants and other factors. Therefore, circulation in lakes is complicated, and we are far from having solved all problems. In this research, only wind is mentioned as a main factor causing circulation in lakes because the wind-induced flow significantly affects water quality in the closed-water area (Mori et al., 2001). In an effort to contribute to the more understanding of the circulation in lakes, this research has been done on the basis of the incompressible Navier-Stokes equations with the simplifying assumption that the flow in lakes is well-mixed laterally in order to develop a two-dimensional,

${ }^{1}$ Laboratory of Bioproduction and Environment Information Sciences, Division of Bioproduction and Environment Information Sciences, Department of Bioproduction and Bioenvironment Sciences, Graduate School of Bioresource and Bioenvironmental Sciences, Kyushu University

* Corresponding author (Email: moriken@bpes.kyushu-u.ac.jp) unsteady, laterally averaged model for simulating the wind-induced flows in lakes.

The Navier-Stokes equations can not be solved analytically in a original form. Therefore, they must be treated by approximation with the help of the discretization methods. In this research, the finite volume method (FVM) was applied for the discretization of the equations. To solve the discretized equations, the SIMPLE algorithm (Patankar, 1980) which has been well-known in the field of fluid dynamics was applied. After the algorithm was programmed in Fortran 90, the model was used to simulate the wind-induced flows under the different areas covered by aquatic plants on the water surface as presented below. Besides examining the variable patterns of the flow field under different covering percentage of aquatic plants, the results of this research is also useful for study of water quality simulation in lakes because flow field simulation is important for water quality simulation in lakes.

\section{MATERIALS AND METHODS}

\section{Governing equations}

The present numerical simulations are concerned with an unsteady-state, two-dimensional, laterally averaged flow, which is governed by a set of partial differential equations. The momentum and continuity equations in their primitive form are shown below :

$$
\begin{aligned}
& \frac{\partial(\rho u)}{\partial x}+\frac{\partial(\rho w)}{\partial z}=0 \\
& \frac{\partial(\rho u)}{\partial t}+\frac{\partial(\rho u u)}{\partial x}+\frac{\partial(\rho u w)}{\partial z}= \\
& -\frac{\partial p}{\partial x}+\frac{\partial}{\partial x}\left(\mu_{x} \frac{\partial u}{\partial x}\right)+\frac{\partial}{\partial z}\left(\mu_{z} \frac{\partial u}{\partial z}\right)
\end{aligned}
$$




$$
\begin{aligned}
& \frac{\partial(\rho w)}{\partial t}+\frac{\partial(\rho w u)}{\partial x}+\frac{\partial(\rho w w)}{\partial z}= \\
& -\rho g-\frac{\partial p}{\partial z}+\frac{\partial}{\partial x}\left(\mu_{x} \frac{\partial w}{\partial x}\right)+\frac{\partial}{\partial z}\left(\mu_{z} \frac{\partial w}{\partial z}\right)
\end{aligned}
$$

Where $u$ and $w$ are the velocities in the $x$ and $z$ directions, respectively, $\rho$ is water density, $p$ is pressure, $g$ is gravity acceleration, $\mu_{x}$ is horizontal eddy viscosity, $\mu_{z}$ is vertical eddy viscosity.

\section{Discretization}

In order to numerically solve the velocity and pressure fields, the equations (1)-(3) above were discretized by the finite-volume method. The method involves integrating the continuity and momentum equations over a two-dimensional control volume on a staggered differential grid (Patankar, 1980), as shown in Fig. 1.

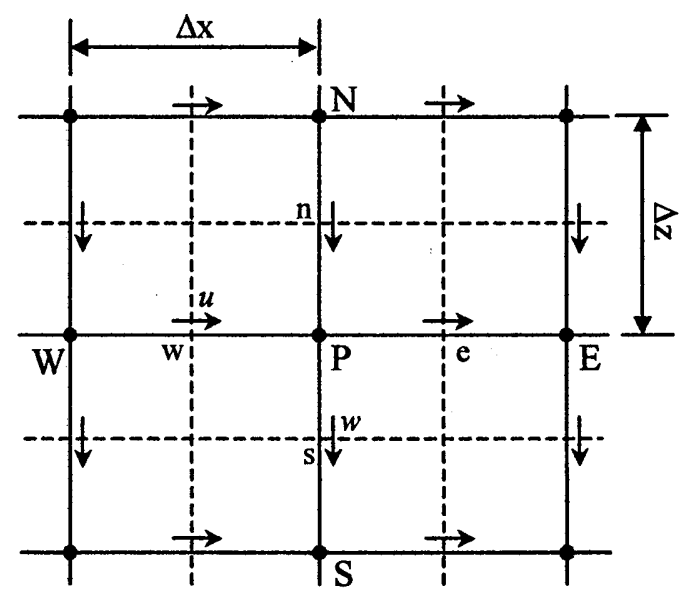

Fig. 1. Staggered grid describing a control volume with flow variables for two-dimensional situation.

In the staggered grid, the calculated domain is divided into control volumes defined by the dashed lines. The pressure is stored at the nodes marked $(\bullet)-$ the intersection of two unbroken grid lines and indicated by the capital letters $\mathrm{P}, \mathrm{W}, \mathrm{E}, \mathrm{N}$ and $\mathrm{S}$. The $u$-velocity components are stored at the east and the west cell faces of the control volume and indicated by the lower case letters $e$ and $w$. The $w$-velocity components are located at the north and south cell faces of the control volume, which are indicated by the lower case letters $n$ and $s$. $\Delta x$ is the sub-interval of the calculated length. $\Delta z$ is the sub-interval of the calculated depth.

After discretization, the discretized continuity equation becomes :

$$
\left[(\rho u)_{e}-(\rho u)_{w}\right] \Delta z+\left[(\rho w)_{s}-(\rho w)_{n}\right] \Delta x=0(4)
$$

and the discretized $u$-momentum equation becomes

$$
a_{e}^{(u)} u_{e}=\sum a_{n b}^{(u)} u_{n b}+b^{(u)}+\left(P_{P}-P_{E}\right) \Delta z
$$

$$
\begin{aligned}
\text { with }: a_{e}^{(u)} & =\frac{\rho_{e}^{o} \Delta x \Delta z}{\Delta t}+a_{E}^{(u)}+a_{w}^{(u)}+a_{s}^{(u)}+a_{N}^{(u)}, \\
b^{(u)} & =u_{e}^{o} \frac{\rho_{e}^{o} \Delta x \Delta z}{\Delta t}
\end{aligned}
$$

and the discretized $w$-momentum equation can be written as:

$$
\begin{gathered}
a_{n}^{(w)} w_{n}=\sum a_{n b}^{(w)} w_{n b}+b^{(w)}+\left(P_{N}-P_{P}\right) \Delta x \\
\text { with }: a_{n}^{(w)}=\frac{\rho_{n}^{o} \Delta x \Delta z}{\Delta t}+a_{E}^{(w)}+a_{w}^{(w)}+a_{s}^{(w)}+a_{N}^{(w)}, \\
b^{(w)}=-\rho_{n} g \Delta x \Delta z+\frac{w_{n}^{o} \rho_{n}^{o} \Delta x \Delta z}{\Delta t}
\end{gathered}
$$

where : $\rho_{e}^{o}, \rho_{n}^{o}, u_{e}^{o}, w_{n}^{o}$ refer to the known values at time $\mathrm{t}$, while all other values are the unknown values at time $t+\Delta t$. The coefficients with superscripts $(u)$ and $(w)$ refer to the coefficients corresponding to $u$ and $w$, respectively. $a_{n b}^{(u)}, a_{n b}^{(w)}$ refer to the neighbour coefficients $a_{E}^{(u)}, a_{W}^{(u)}, a_{N}^{(u)}, a_{s}^{(u)}, a_{E}^{(u)}, a_{W}^{(u)}, a_{N}^{(u)}$ and $a_{s}^{(u)}$, which account for the combined convection-diffusion influence at the control-volume faces of $u$-cell and $w$-cell, respectively. The values of these coefficients are obtained on the basis of the power-law scheme (Patankar, 1980). The velocity components $u_{n b}$ and $w_{n b}$ are those at the neighbouring nodes outside the control volume. $P_{E}, P_{w}, P_{N}$ and $P_{S}$ refer to the pressure at the east, the west, the north and the south faces of the control volume, respectively.

\section{Boundary Conditions}

For calculation of velocities, boundary conditions at the bottom and the walls of lake are taken as the no-slip boundary condition $(u=w=0)$. On the free water surface, $w$ is set to zero, and $u$, which is set to $3 \%$ of wind speed at $10 \mathrm{~m}$ above water surface, is applied to the so-called reflection technique (Peyret and Taylor, 1983).

\section{Numerical Algorithm}

To solve equations (4)-(6), the SIMPLE algorithm (Patankar, 1980), which is essentially a guess-and-correct procedure for the calculation of pressure on the staggered grid introduced above, is applied. To initiate the SIMPLE calculation process, a pressure field $p^{*}$ is guessed. The discretised momentum equations (5) and (6) are solved using the guessed pressure field to yield velocity components $u^{*}$ and $w^{*}$ as follows :

$$
\begin{aligned}
& a_{e}^{(u)} u_{e}^{*}=\sum a_{n b}^{(u)} u_{n b}^{*}+b^{(u)}+\left(P_{P}^{*}-P_{E}^{*}\right) \Delta z \\
& a_{n}^{(w)} w_{n}^{*}=\sum a_{n b}^{(u)} w_{n b}^{*}+b^{(w)}+\left(P_{N}^{*}-P_{P}^{*}\right) \Delta x
\end{aligned}
$$

Defining the correction $p$ ' as the difference between the correct pressure field $p$ and the guessed pressure field $p^{*}$, so that :

$$
p=p^{*}+p
$$

Similarly defining the velocity correction $u^{\prime}$ and $w^{\prime}$ to relate the correct velocities $u$ and $w$ to the guessed 
velocities $u^{*}$ and $w^{*}$ :

$$
\begin{aligned}
& u=u^{*}+u^{\prime} \\
& w=w^{*}+w^{\prime}
\end{aligned}
$$

By subtracting equations (7) and (8) from (5) and (6) respectively, it gives

$$
a_{e}^{(u)}\left(u_{e}-u_{e}^{*}\right)=\sum a_{n b}^{(u)}\left(u_{n b}-u_{n b}^{*}\right)+\left[\left(P_{P}-P_{P}^{*}\right)-\left(P_{E}-P_{E}^{*}\right)\right] \Delta z
$$

$$
a_{n}^{(w)}\left(w_{n}-w_{n}^{*}\right)=\sum a_{n b}^{(w)}\left(w_{n b}-w_{n b}^{*}\right)+\left[\left(P_{N}-P_{N}^{*}\right)-\left(P_{P}-P_{P}^{*}\right)\right] \Delta x
$$

Using the correction formulae (9)-(11), the equations (12) and (13) can be written as follows :

$$
\begin{aligned}
& a_{e}^{(u)} u_{e}^{\prime}=\sum a_{n b}^{(u)} u_{n b}^{\prime}+\left(P_{P}^{\prime}-P_{E}^{\prime}\right) \Delta z \\
& a_{n}^{(w)} w_{n}^{\prime}=\sum a_{n b}^{(w)} w_{n b}^{\prime}+\left(P_{N}^{\prime}-P_{P}^{\prime}\right) \Delta x
\end{aligned}
$$

In the SIMPLE algorithm, the terms $\sum a_{n b}^{(u)} u_{n b}^{\prime}$ and $\sum a_{n b}^{(w)} w_{n b}^{\prime}$ are dropped to simplify equations (14) and (15) for velocity corrections. Therefore, we obtain :

$$
\begin{aligned}
& u_{e}^{\prime}=\frac{\Delta z}{a_{e}^{(u)}}\left(P_{P}^{\prime}-P_{E}^{\prime}\right) \\
& w_{n}^{\prime}=\frac{\Delta x}{a_{n}^{(w)}}\left(P_{N}^{\prime}-P_{P}^{\prime}\right)
\end{aligned}
$$

Substituting equations (16) and (17) into (10) and (11) gives :

$$
\begin{aligned}
& u_{e}=u_{e}^{*}+\frac{\Delta z}{a_{e}^{(u)}}\left(P_{P}^{\prime}-P_{E}^{\prime}\right) \\
& w_{n}=w_{n}^{*}+\frac{\Delta x}{a_{n}^{(u)}}\left(P_{N}^{\prime}-P_{P}^{\prime}\right)
\end{aligned}
$$

Similarly we have :

$$
\begin{aligned}
& u_{w}=u_{w}^{*}+\frac{\Delta z}{a_{w}^{(u)}}\left(P_{W}^{\prime}-P_{P}^{\prime}\right) \\
& w_{s}=w_{s}^{*}+\frac{\Delta x}{a_{s}^{(w)}}\left(P_{P}^{\prime}-P_{s}^{\prime}\right)
\end{aligned}
$$

Substituting equations (18)-(21) into the discretised continuity equation (4), we draw the pressure-correction equation which plays an important part in the SIMPLE algorithm as follows :

$$
\begin{aligned}
a_{P} P_{P}^{\prime}= & a_{E} P_{E}^{\prime}+a_{w} P_{W}^{\prime}+a_{N} P_{N}^{\prime}+a_{S} P_{s}^{\prime}+\left[\left(\rho u^{*}\right)_{w}-\left(\rho u^{*}\right)_{e}\right] \Delta z \\
& +\left[\left(\rho w^{*}\right)_{n}-\left(\rho w^{*}\right)_{s}\right] \Delta x
\end{aligned}
$$

where : $a_{P}=a_{E}+a_{W}+a_{N}+a_{s}$

$$
\begin{aligned}
& a_{E}=\rho_{e} \frac{(\Delta z)^{2}}{a_{e}} ; a_{W}=\rho_{W} \frac{(\Delta z)^{2}}{a_{w}} ; \\
& a_{N}=\rho_{N} \frac{(\Delta x)^{2}}{a_{n}} ; a_{S}=\rho_{S} \frac{(\Delta x)^{2}}{a_{s}}
\end{aligned}
$$

The procedure of the SIMPLE algorithm is summarized

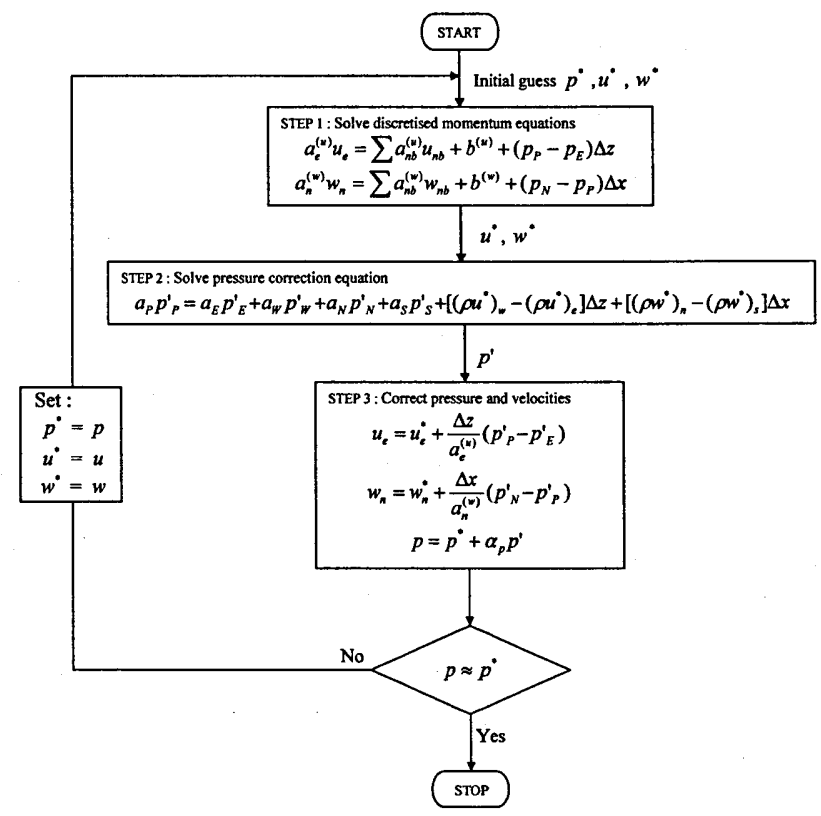

Fig. 2. Flow chart of the SIMPLE algorithm.

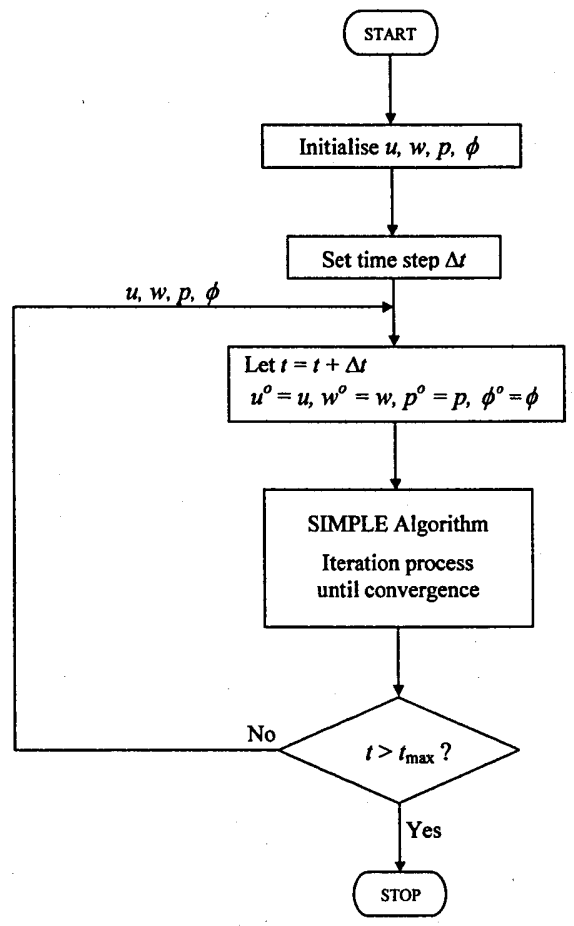

Fig. 3. Flow chart for unsteady flow calculation with application of the SIMPLE algorithm.

in a flow chart as shown in Fig. 2.

Where $\alpha_{p}$ is the pressure under-relaxation factor, the other symbols were already explained above.

The SIMPLE algorithm is extended to transient calculations to reach the objective of this research. A flow chart for the calculation of unsteady-state flows will be shown in Fig. 3.

In performing the SIMPLE algorithm to solve the velocities, the TDMA (Tri-Diagonal Matrix Algorithm) or Thomas' algorithm, which has become almost standard for the treatment of tridiagonal systems of equations (Anderson, 1995), is employed by line-by-line method. 
To solve a general two-dimensional discretised equation with a form such as:

$$
a_{P} \phi_{P}=a_{W} \phi_{W}+a_{E} \phi_{E}+a_{S} \phi_{S}+a_{N} \phi_{N}+b
$$

The equation can be re-arranged in the form :

$$
-a_{S} \phi_{S}+a_{P} \phi_{P}-a_{N} \phi_{N}=a_{W} \phi_{W}+a_{E} \phi_{E}+b
$$

Considering the discretized equations for the grid points along a chosen line (shown by $\bullet$ ), we can see that they contain the variables at the grid points (shown by $\square$ ) along the two neighboring lines $\left(\phi_{W}\right.$ and $\left.\phi_{E}\right)$. If the right hand side of the equation (24) is assumed to be temporarily known, the equations along the chosen line (shown by -) would look like one-dimensional equations and could be solved by the TDMA. Subsequently the calculation is moved to the next line. If we sweep from west to east, the values of $\phi_{W}$ to the west of point $\mathrm{P}$ are known from the calculation performed on the previous line. Values of $\phi_{E}$ to its east, however, are unknown, so the solution process must be iterative. The line-by-line calculation procedure is repeated several times until a converged solution is obtained. The method is illustrated in Fig. 4 below (Versteeg and Malalasekera, 1995).

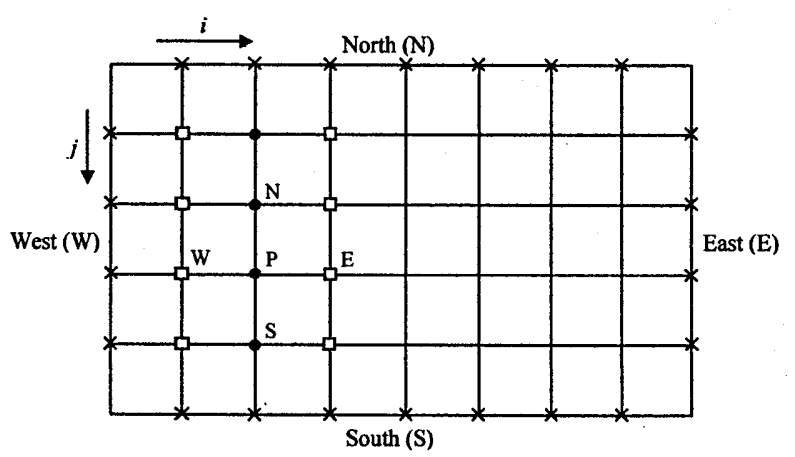

Fig. 4. Illustration of the line-by-line method.

where the points $(\bullet)$ at which the values are calculated, the points $(\square)$ are considered to be temporarily known, the points $(x)$ are known boundary values.

\section{Data requirement for the model}

To calculate the velocities of flow field induced by wind, the data of wind speed must be collected. In addition to wind speed data, the data on lake size such as the average depth of lake $(H)$, the average length of lake $(L)$ must be also collected.

\section{Calibrated coefficients}

In this model, two coefficients proposed to calibrate are the vertical eddy viscosity $\left(\mu_{z}\right)$ and the horizontal eddy viscosity $\left(\mu_{x}\right)$. The vertical eddy viscosity $\left(\mu_{z}\right)$ is calculated by the following formula (Bengtsson, 1973) :

$$
\mu_{z}=c \times h \times W
$$

where $h$ is average depth of lake, $W$ is wind speed, $c$ is constant $\left(=2 \times 10^{-5}\right)$

The horizontal eddy viscosity $\left(\mu_{x}\right)$ is taken according to the vertical eddy viscosity $\left(\mu_{z}\right): \mu_{x}=100 \times \mu_{z}$

\section{RESULTS AND DISCUSSION}

To verify the model, Tabiishidani lake, which is located in Sasaguri - Fukuoka prefecture in Japan, was chosen. The lake has an average depth of $2.2 \mathrm{~m}$. The length is about $80 \mathrm{~m}$. In general, the volume of inflow and outflow is zero; that is, there are no changes in water level.

In a cross-section of the lake, the length is sub-divided into intervals of $2 \mathrm{~m}$, the depth is sub-divided into intervals of $0.2 \mathrm{~m}$ to create control volumes with the size $(2 \mathrm{~m} \times 0.2 \mathrm{~m})$. The calculated domain is arranged on a staggered grid as illustrated in Fig. 1 above. The time step $(\Delta t)$ is set to $1800(\mathrm{~s})$. The simulated cases in this research are summerized in Table 1 below.

The results of simulation cases are presented in the Figs. $5-10$ below.

Fig. 10 indicates that the vertical distribution of $u$-velocity in lakes is different between the part of the lake covered by aquatic plants and the part without aquatic plants. It can be seen that in the center of the lake, the flow current in the layers in the top one-third of the depth has the same direction with wind direction while

Table 1. Computational cases.

\begin{tabular}{ccc}
\hline Case & $\begin{array}{c}\text { Wind speed above } \\
\text { water surface }(\mathrm{m} / \mathrm{s}) \\
\text { (measured at 14:30 on } \\
\text { June 26, 2003) }\end{array}$ & $\begin{array}{c}\text { The assumed } \\
\text { covering } \\
\text { percentage of aquatic } \\
\text { plants (\%) }\end{array}$ \\
\hline 1 & 2.0 & 0 \\
2 & 2.0 & 20 \\
3 & 2.0 & 35 \\
4 & 2.0 & 50 \\
5 & 2.0 & 75 \\
\hline
\end{tabular}

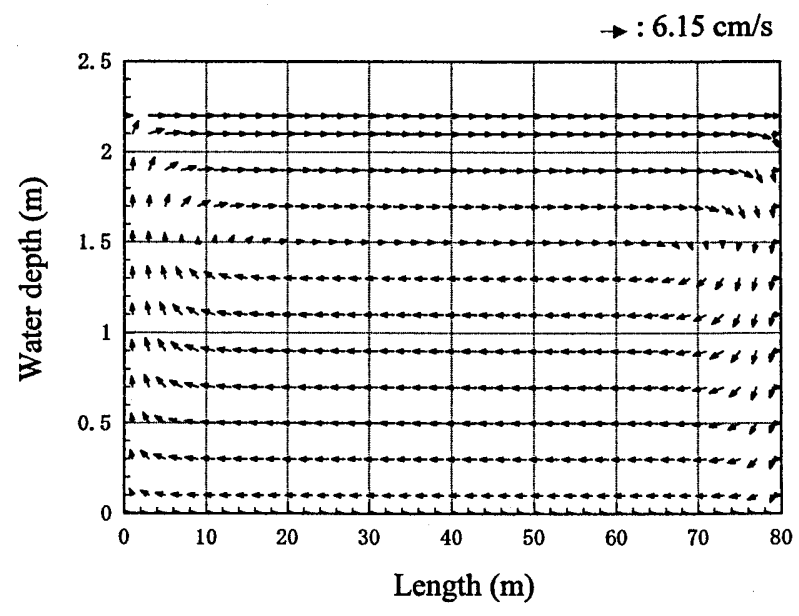

Fig. 5. Wind-induced flow in the lake without the covering of aquatic plants under wind speed equal to $2 \mathrm{~m} / \mathrm{s}$ (measured at 14:30 on June 26, 2003). 


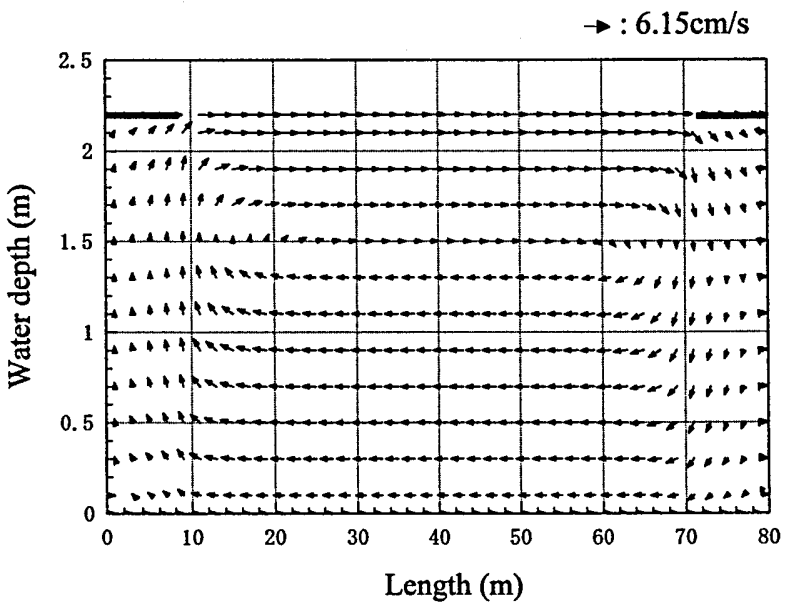

Fig. 6. Wind-induced flow in the lake with $20 \%$ of water surface area assumed to be covered by aquatic plants under wind speed equal to $2 \mathrm{~m} / \mathrm{s}$ (measured at 14:30 on June 26, 2003).

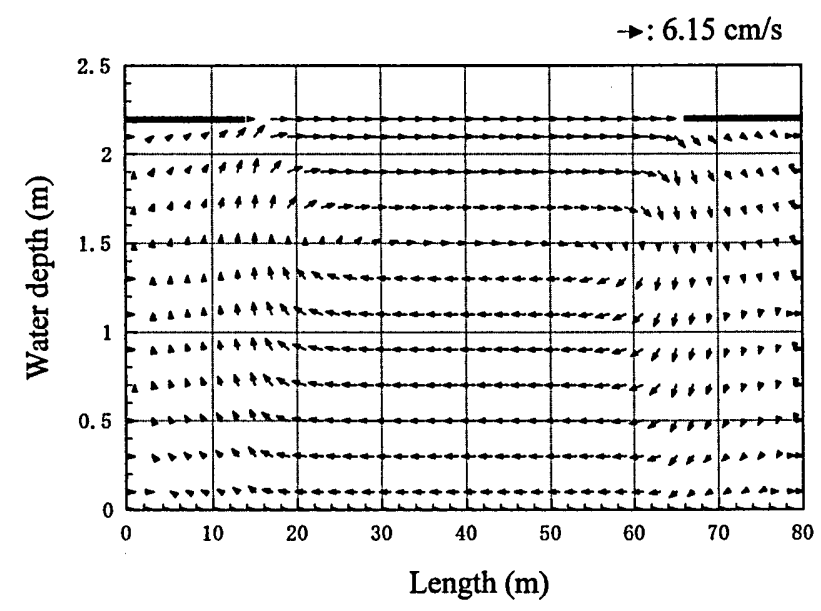

Fig. 7. Wind-induced flow in the lake with $35 \%$ of water surface area assumed to be covered by aquatic plants under wind speed equal to $2 \mathrm{~m} / \mathrm{s}$ (measured at 14:30 on June 26, 2003).

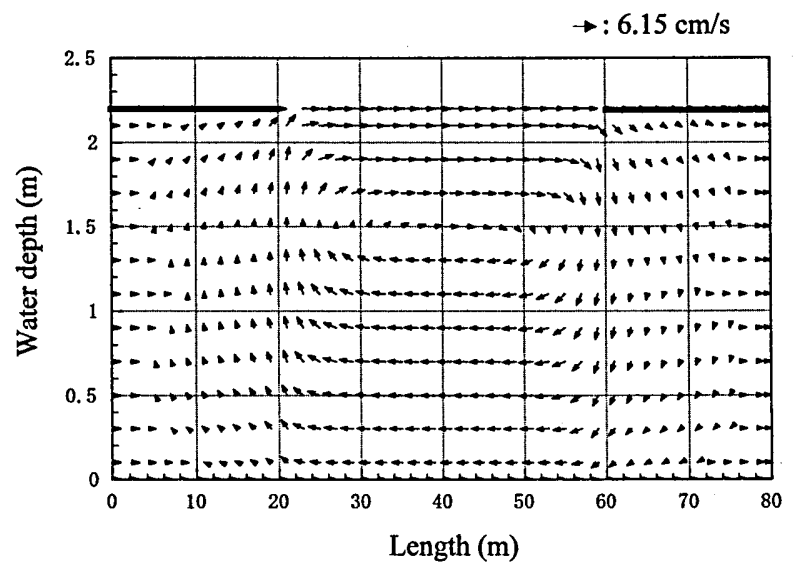

Fig. 8. Wind-induced flow in the lake with $50 \%$ of water surface area assumed to be covered by aquatic plants under wind speed equal to $2 \mathrm{~m} / \mathrm{s}$ (measured at 14:30 on June 26, 2003).

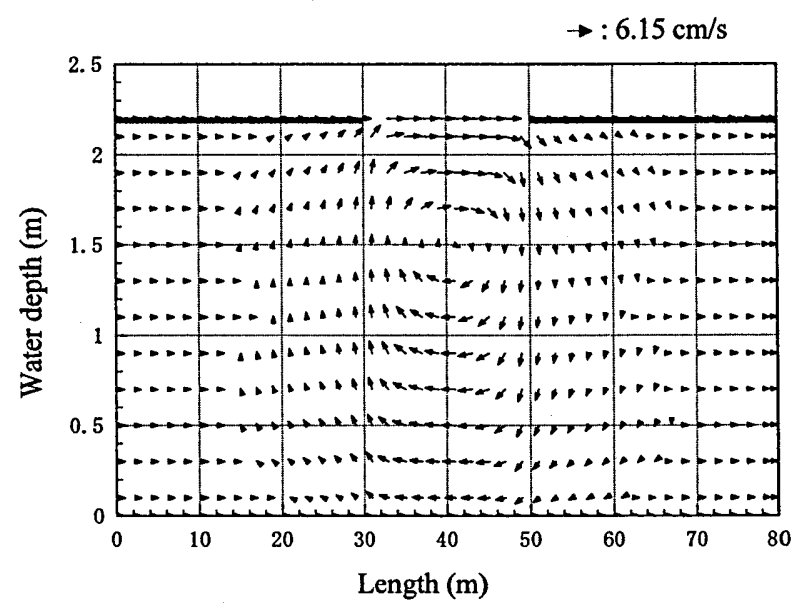

Fig. 9. Wind-induced flow in the lake with $75 \%$ of water surface area assumed to be covered by aquatic plants under wind speed equal to $2 \mathrm{~m} / \mathrm{s}$ (measured at 14:30 on June 26, 2003).

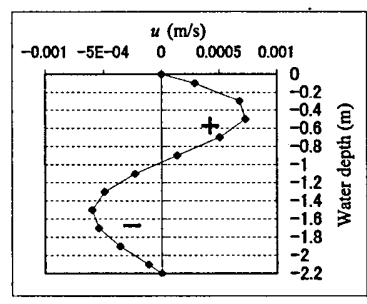

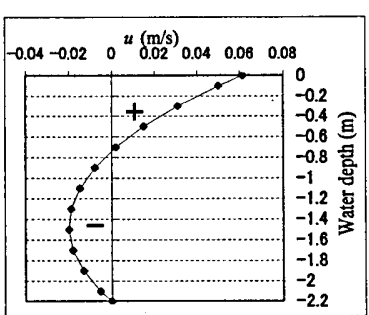

b
Fig. 10. The typical profiles of $u$-velocity distribution along the depth of the lake.

a-below the surface area covered by aquatic plants; b-below the surface area without aquatic plants.

the flow current belonging to the bettom two-thirds of the depth has the inverse direction with wind speed.

The results of simulation above indicate that wind is the main factor which can help lakes circulate by mixing waters in upper layers into the lower layers.

Fig. 5-Fig. 9 above clearly show that aquatic plants significantly affected the wind-induced flow pattern in lakes. When the covering percentage of aquatic plants changes, the flow pattern also changes so clearly that it can be easily identified from the figures above. The more aquatic plants cover on the water surface the smaller the region of circulation becomes. This tendency can be seen from Fig. 5 where circulation in the lake covers almost the cross section of the lake corresponding to the case without the covering of aquatic plants. As the covering percentage of aquatic plants increases from the sides, the region of circulation would be narrowed gradually from the sides to the center of the lake. The region of circulation becomes smallest when the covering percentage of aquatic plants is maximum $(75 \%)$ as can be seen in Fig. 9 .

Fig. 11 indicates the change in $u$-velocity distribution corresponding to cases of aquatic plants covering 


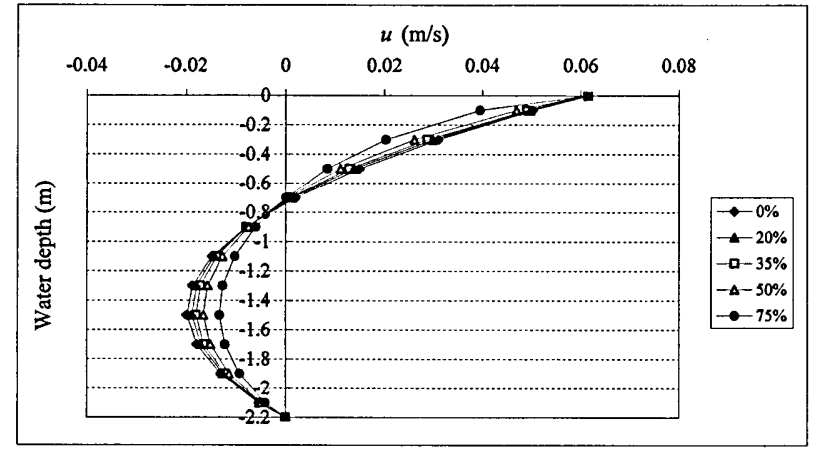

Fig. 11. The profiles of $u$-velocity distribution corresponding to cases of aquatic plants covering on the water surface of the lake.

on the water surface of the lake. To examine this change in quantity, the flow rate of each case is calculated by the following formula:

$$
q_{r}=\int_{0}^{h} u d z
$$

where $q_{r}$ is the flow rate in circulation per unit width $\left(\mathrm{cm}^{2} / \mathrm{s}\right), h$ is the top one-third of the depth $(\mathrm{cm}), u$ is water velocity in the circulation.

The results of calculation were expressed in the Fig. 12 below :

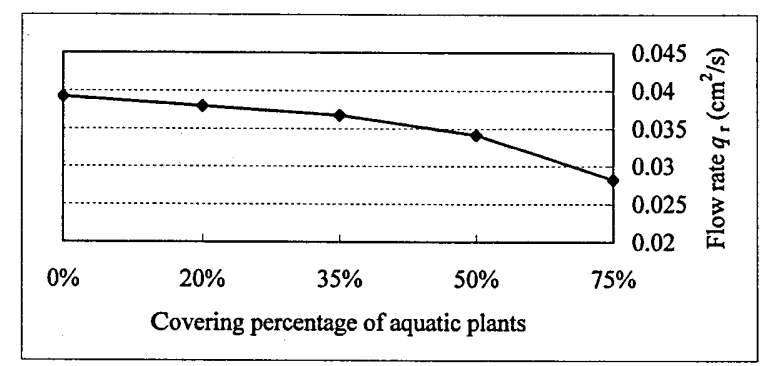

Fig. 12. Relationship between the flow rate and the covering percentage of aquatic plants.

It can be seen clearly from Fig. 12 that the flow rate in circulation of the lake is inversely proportional to the covering percentage of aquatic plants.

In short, aquatic plants affect not only the flow pattern but also the flow rate in circulation of the lake.

\section{CONCLUSIONS}

From the results of simulation presented above, some conclusions can be drawn as follows :

- Wind plays an important part in circulation of lakes. The higher wind speed is, the better mixing capability of lakes is

- Aquatic plants can significantly affect on both the pattern and the rate of the wind-induced flow in lakes. The wind-induced flow, in turn, can affect water quality in lakes.

- As aquatic plants develop from the sides, the region of circulation tends to be narrowed gradually from the sides to the center of lakes.

- The shape of vertical distribution of $u$-velocity in lakes differs from the region of lakes covered by aquatic plants to the region without the covering of quatic plants.

- This research is studied on the basis of some simplifying assumptions namely :

$+\quad$ The flow in lakes is well-mixed laterally.

+ The density of water is homogeneous.

\section{REFERENCES}

Anderson, J. D 1995 Computational fluid dynamics. McGraw-Hill, Inc., New York, pp. 150-442

Bengtsson, L 1973 Conclusions about turbulent exchange coefficients from model studies. In "International Symposium Hydrology of lakes", Helsinki, IAHS Publ. No. 109, pp. 306-312

Mori, K., S. Shikasho and K. Hiramatsu 2001 Wind-induced flow in a closed-water area with discrete wind shear. Fisheries Engineering 37(3): 195-201

Nyhoff, L. and S. Leestma 1999 Introduction to Fortran 90. Prentice Hall, America, pp. 15-196

Nyhoff, L. and S. Leestma 1997 Fortran 90 for Engineer and Scientists. Prentice Hall, America, pp. 30-46

Patankar, S. V 1980 Numerical heat transfer and fluid flow. McGraw-Hill, New York, pp. 41-143

Peyret, R. and T. D. Taylor 1983 Computational methods for fluid flow. Springer-Verlag, New York Heidelberg Berlin, pp. $150-153$

Sündermann, J 1979 Numerical modelling of circulation in lakes. In "Hydrodynamics of lakes" ed. by H. G Walter and H. M Clifford, Elsevier Scientific Publishing Company, Amsterdam-Oxford-New York, pp. 1-5

Versteeg, H. K. and W. Malalasekera 1995 An introduction to computational fluid dynamics. Longman House, Burnt Mill, Harlow, pp. 135-159 